\title{
CONDENSING OSTEITIS OF THE CLAVICLE: DOES IT EXIST?
}

\author{
MEL W. JONES, HELEN CARTY, JOHN F. TAYLOR, SALIH K. IBRAHIM
}

From the Royal Liverpool Children's Hospital, Liverpool

\begin{abstract}
Condensing osteitis of the clavicle was first described as a disease entity in 1974. There is painful localised swelling of the clavicle of undetermined origin, with increased radio-density, but an infective aetiology has not been excluded by previous authors.

We report three children with the clinical and radiological findings of 'condensing osteitis'. Two of them had raised levels of antistaphylolysin titres and all responded to antibiotic therapy. We conclude that condensing osteitis is due to low-grade staphylococcal osteomyelitis; biopsy and treatment by antibiotics is recommended.
\end{abstract}

Condensing osteitis of the clavicle was first described by Brower, Sweet and Keats (1974), as a syndrome causing pain on abduction of the arm with swelling over the medial end of a clavicle which showed radiographic sclerosis. Since then, 25 more cases have been described (Solovjev 1976; Simpson 1978; Teates et al 1978; Tilly et al 1978; Petersen 1980; Duró et al 1981; Appell et al 1983; Cone et al 1983; Weiner et al 1984; Franquet et al 1985; Kruger, Rock and Munro 1987; Smith, Yuppa and Watson 1988). The syndrome has been considered to be a response to mechanical stress but no serious attempt was made to exclude infection in any of these cases.

We report three cases which could be classed as 'condensing osteitis'; serological tests showed that osteomyelitis was the most likely cause in two, whilst the third refused full investigation.

\section{CASE REPORTS}

Case 1. An eight-year-old girl presented with pain and diffuse swelling over the medial end of the right clavicle for a few days, with no history of trauma. She was otherwise well. Radiographs showed a periosteal reaction along the lower border of the clavicle (Fig. 1). Over the

M. W. Jones, FRCS, FRCS Ed, Orthopaedic Registrar

H. Carty, FRCPI, FRCR. Consultant Radiologist

J. F. Taylor, MD, MCh Orth, FRCS, Consultant Orthopaedic Surgeon

S. K. Ibrahim, MRCPath, Consultant Histopathologist

Royal Liverpool Children's Hospital, Alder Hey, Liverpool L12 2AP, England.

Correspondence should be sent to Mr M. W. Jones at 26 Moss Close, Willaston, South Wirral L64 2XQ, England.

(C) 1990 British Editorial Society of Bone and Joint Surgery $0301-620 X / 90 / 3062 \$ 2.00$

J Bone Joint Surg [ Br] 1990; 72-B : 464-7.

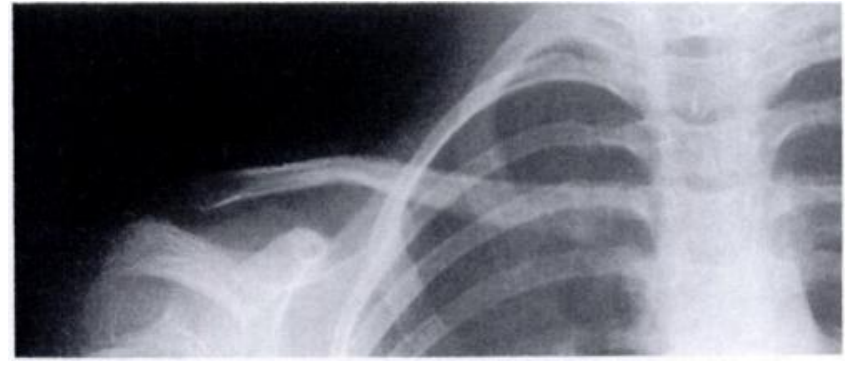

Fig. 1

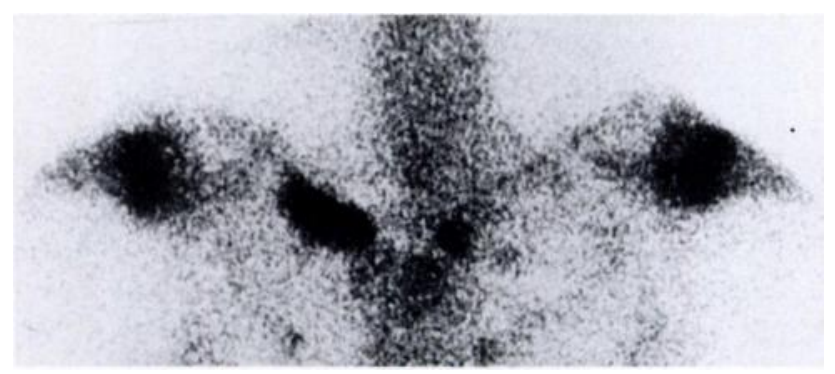

Fig. 2

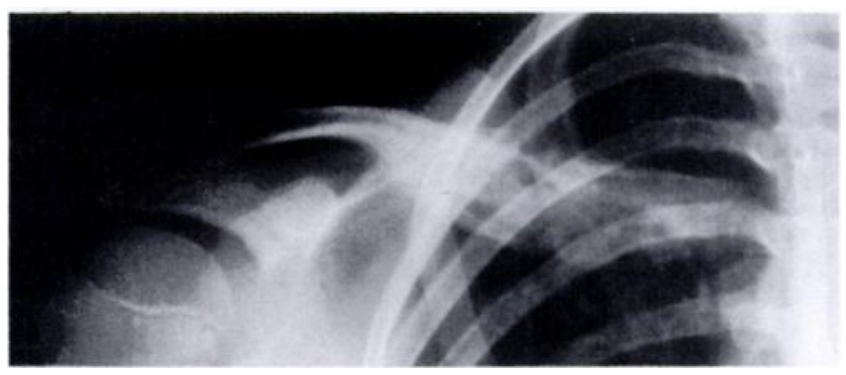

Fig. 3

Case 1. Figure 1. At the onset of symptoms, there is a periosteal reaction along the lower border of the clavicle. Figure 2 - An isotope scan showed increased uptake confined to the medial end of the clavicle. Figure 3 - Five months later there is progression of bony thickening. 


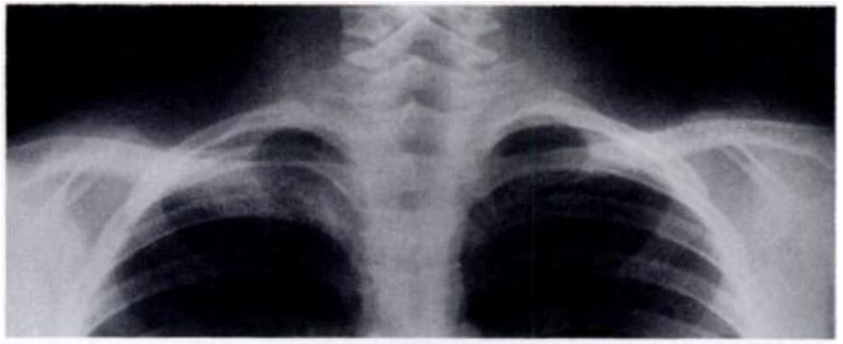

Fig. 4

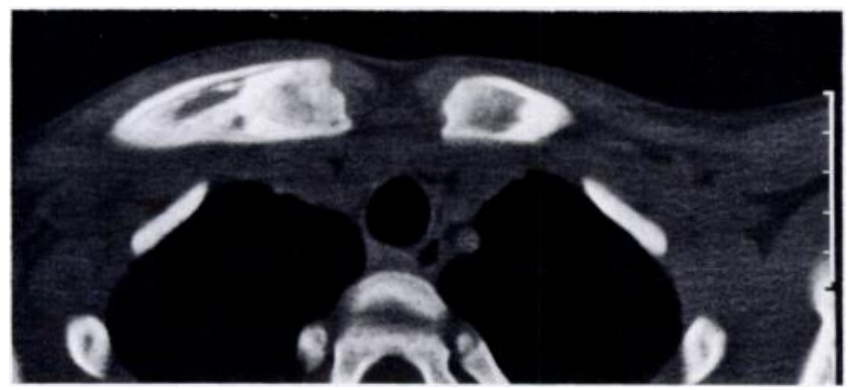

Fig. 5

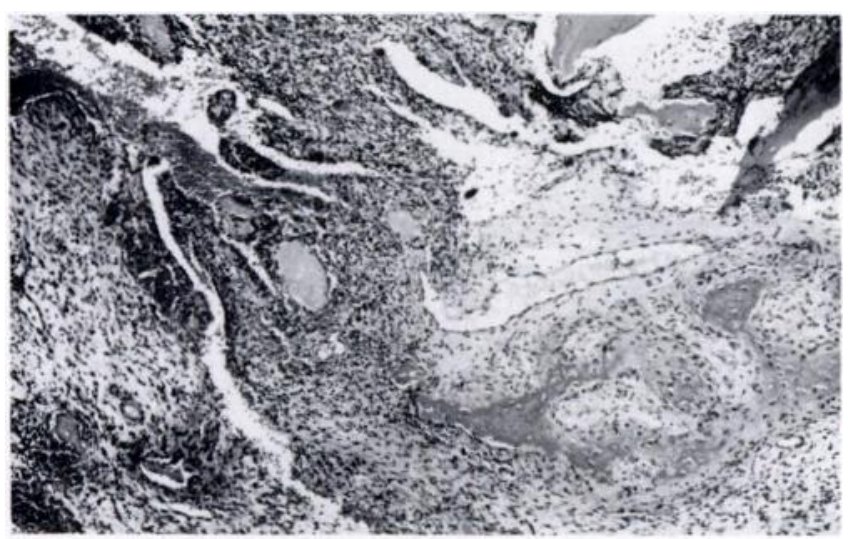

Fig. 6

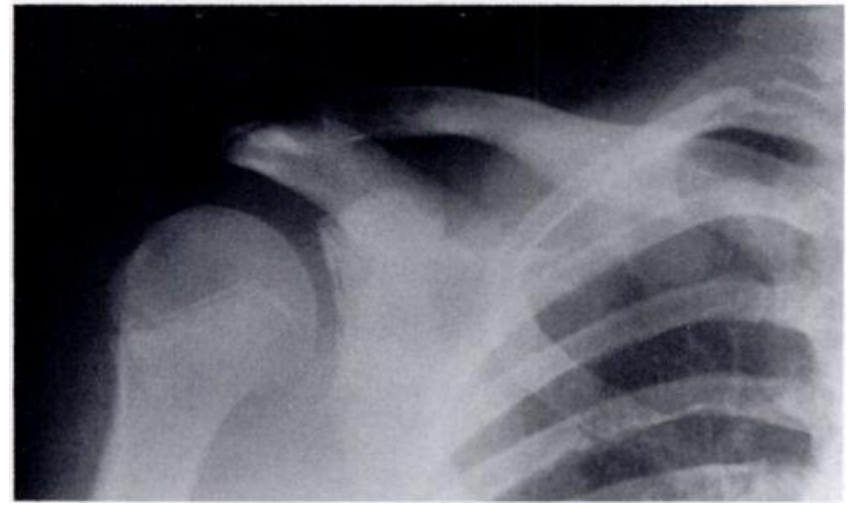

Fig. 7

Case 2. Figure 4 Radiograph at presentation showing a periosteal reaction along the lower border of the clavicle with loss of corticomedullary differentiation. Figure 5 - CT scan shows an expanded cortex but no soft tissue involvement. Figure 6 - Histology of the biopsy shows granulation tissue including a heavy mixed inflammatory cell infiltrate (left) with woven bone (lower right) and lamellar bone trabeculae (upper right). (H\&E $\times 40)$. Figure 7 - Eight months after the biopsy there is further thickening and sclerosis. next month, the pain persisted and the swelling increased in size; further radiographs showed the medial end of the clavicle to be expanded with some sclerosis and a bubbly appearance. An isotope scan showed increased uptake confined to the abnormal region (Fig. 2). The white cell count (WCC) was $9.9 \times 10^{9} / 1$, with a normal differential count and the ESR was $10 \mathrm{~mm} / \mathrm{hr}$.

At surgical exploration necrotic bone and granulation tissue was found but no organisms were cultured. Histological examination revealed new bone formation with bony trabeculae covered by large osteoblasts. Neutrophil polymorphs were numerous with occasional plasma cells. The appearances were those of an active non-specific inflammatory process. Osteomyelitis was thought to be the most likely cause and the patient was treated with erythromycin $250 \mathrm{mg}$ four times daily. Five months later, the swelling had increased in size and remained tender. The radiograph showed progression of the bony thickening (Fig. 3). At re-exploration, no focus of infection was identified and cultures were sterile. Erythromycin was continued for a total of nine months; 14 months after the onset of symptoms the patient remains well although the swelling persists and is occasionally tender.

Case 2. A 12-year-old boy presented with a four-month history of spontaneous aching and a $7 \times 5 \mathrm{~cm}$ swelling of the medial end of the right clavicle. His WCC was $10 \times 10^{9} / 1$, with $64 \%$ neutrophils showing moderate toxic granulation, and his ESR was $15 \mathrm{~mm} / \mathrm{hr}$. A Mantoux test was negative. Radiographs showed a periosteal reaction along the lower border of the clavicle with loss of corticomedullary differentiation (Fig. 4). A CT scan showed a dense cortex with an expanded clavicle but no soft tissue swelling (Fig. 5). An isotope scan showed increased uptake confined to the abnormal area; the sternum was normal.

A biopsy showed subperiosteal new bone formation and granulation tissue (Fig. 6). There was a heavy mixed inflammatory cell infiltrate, with neutrophils predominating, around woven and lamellar bone trabeculae. Stains for bacteria and acid fast bacilli were negative. The appearances were those of an active, non-specific inflammatory process. Cultures, including those for tuberculosis, were sterile. Serology did not show elevated levels of brucella and salmonella antigens or antistreptococcal antibody titres but anti-alpha haemolysin (antistaphylolysin) titres were grossly raised at 6 to 8 units $/ \mathrm{ml}$ (normally 2 units/ml or less).

The patient was treated with $500 \mathrm{mg}$ of cephradine four times daily for eight weeks. Four months after the biopsy he was asymptomatic with a WCC of $9 \times 10^{9} / 1$, an ESR of $1 \mathrm{~mm} / \mathrm{hr}$ but a rising titre of anti-alpha haemolysin titres of 8 units $/ \mathrm{ml}$. Eight months after biopsy the ache had returned and the medial end of the clavicle showed further thickening and sclerosis (Fig. 7). His anti-alpha haemolysin titres were now over 8 units $/ \mathrm{ml}$. His WCC was $10.8 \times 10^{9} / 1$ and ESR $<1 \mathrm{~mm} / \mathrm{hr}$. At 
latest review, he was on cephradine $100 \mathrm{mg} / \mathrm{kg} /$ day and fucidin $500 \mathrm{mg}$ three times daily.

Case 3. A 10-year-old girl developed pain and swelling in the region of the left clavicle and a radiograph showed a periosteal reaction and early expansion of the midclavicle (Fig. 8). A month later there was further bony expansion with a bubbly appearance; these films were initially thought to be consistent with a healing fracture.

Seven months after the onset, the symptoms persisted and the swelling was $6 \times 6 \mathrm{~cm}$. Her WCC was $7 \times 10^{9} / 1$ with $55 \%$ neutrophils, her ESR $33 \mathrm{~mm} / \mathrm{hr}$ and her Mantoux test negative. By then radiographs showed a huge expansion of dense amorphous bone with a well consolidated reaction cloaking the clavicle distally (Fig. 9). An isotope scan showed a marked increase in uptake over the abnormal area (Fig. 10) and a CT scan showed gross expansion of the clavicle with dense bone. The original corticomedullary junction had been lost, but there was no soft tissue involvement.

Biopsy showed mature lamellar and immature bone trabeculae (Fig. 11), the latter with marked osteoblastic activity and a mild lymphocytic infiltrate in the intervening fibrous tissue. No neutrophil leucocytes, plasma cells or granulomata were identified. Stains for bacteria and acid fast bacilli were negative. The appearance was that of a chronic non-specific inflammatory process with new bone formation. Tissue cultures, including TB, were sterile. Serology did not show elevated levels of brucella or salmonella antigens or antistreptococcal antibody titres but anti-alpha haemolysin titres were raised at 2 to 4 units $/ \mathrm{ml}$.

Treatment was with cephradine $500 \mathrm{mg}$ four times daily for six weeks. Two months after biopsy she was asymptomatic with a WCC of $7 \times 10^{9} / 1$, an ESR of $41 \mathrm{~mm} / \mathrm{hr}$ and anti-alpha haemolysin titres of 2 to 4 units/ $\mathrm{ml}$. Four months after biopsy the WCC was $8.6 \times 10^{9} / 1$, the ESR was $67 \mathrm{~mm} / \mathrm{hr}$ and anti-alpha haemolysin titres were normal at 2 units $/ \mathrm{ml}$. Seven months after biopsy she remained asymptomatic and the bony swelling was becoming smaller (Fig. 12).

\section{DISCUSSION}

We have presented the clinical, radiological and histological findings in three children with unilateral painful swelling of the clavicle. Non-traumatic clavicular swelling is rare but has been previously reported in acute and chronic infection (Donovan and Shah 1982; Mollan, Craig and Biggart 1984; Franklin, Parker and King 1987) and in malignant disease (Franklin et al 1987; Smith et al 1988) including leukaemia (Healey et al 1985).

Brower et al (1974), on the basis of two patients, proposed a previously unrecognised disease, condensing osteitis. However, our results lead us to believe that this condition has an infective origin. The two original cases described by Brower et al had dissimilar clinical findings. One admitted to symptoms only after sclerosis of the medial end of the clavicle had been found on a routine chest radiograph; the other complained of non-specific supraclavicular pain aggravated by shoulder abduction. Radiographs of one case showed 'amorphous sclerosis' and of the other 'minimal sclerosis' of the medial end of the clavicle. Histological reports of 'increase in amount and thickness of cancellous bone' and a 'periosteal reaction' were not specific. No attempt was made to exclude infection and no mention was made of WCC, ESR, bacteriological cultures or serological studies.

Of the other 25 cases reported in the literature, only Appell et al (1983), Weiner et al (1984) and Kruger et al (1987) comment on the WCC and ESR. Only Petersen (1980), Appell et al (1983) and Kruger et al (1987) mention bacteriological culture of biopsy material in some of their cases. There is no report of an attempt to exclude infection by serology.

The histological findings in our first two cases were of an acute on chronic non-specific inflammatory process (osteomyelitis) and in the third the picture is that of chronic osteomyelitis. Although culture of biopsy material was negative in all our cases, this is not unusual in clavicular sepsis and does not exclude it (Mollan et al 1984). Neutrophils showing toxic granulations in one patient, a raised ESR in another with both having raised levels of antistaphylococcal antibodies is very suggestive of staphylococcal osteomyelitis in the absence of other foci of infection. One patient refused blood tests for serology.

We therefore believe that condensing osteitis of the clavicle is not a separate clinical entity but due to lowgrade osteomyelitis. The preliminary management of such patients should include a FBC, ESR, isotope scan, Mantoux test and blood serology to exclude infection. A CT scan is useful but we feel that biopsy is mandatory to obtain material for histology and bacteriological culture.

Previous methods of treatment have included surgical excision (Brower et al 1974; Petersen 1980; Appell et al 1983; Franquet et al 1985), anti-inflammatory drugs (Weiner et al 1984) and radiation (Appell et al 1983; Cone et al 1983; Kruger et al 1987) with varying results. We believe the treatment of this condition should be conservative, using antistaphylococcal antibiotics.

We are grateful to Mr D. G. Carden, MCh Orth, FRCS, of the Southport General Infirmary for allowing us to report details of his case and to Mr Fitz-Simon and the photographic department of the Royal Liverpool Children's Hospital, Alder Hey, for producing the illustrations.

No benefits in any form have been received or will be received from a commercial party related directly or indirectly to the subject of this article.

\section{REFERENCES}

Appell RG, Oppermann HC, Becker W, et al. Condensing osteitis of the clavicle in childhood: a rare sclerotic bone lesion. Review of literature and report of seven patients. Pediatr Radiol 1983; 13: 301-6.

Brower AC, Sweet DE, Keats TE. Condensing osteitis of the clavicle : a new entity. $A J R$ 1974; 121:17-21. 


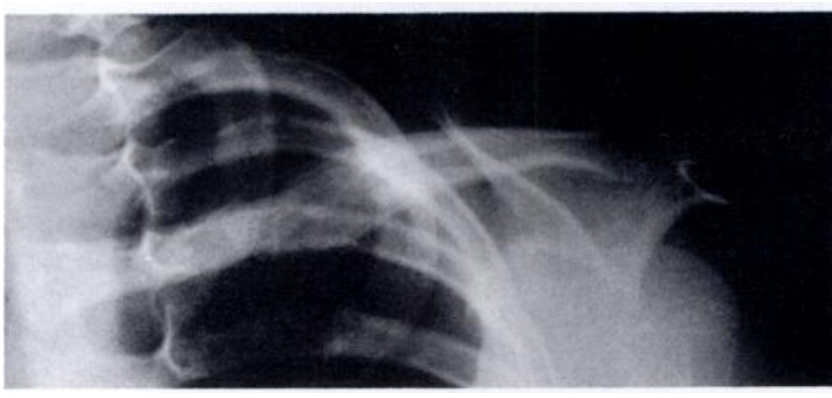

Fig. 8

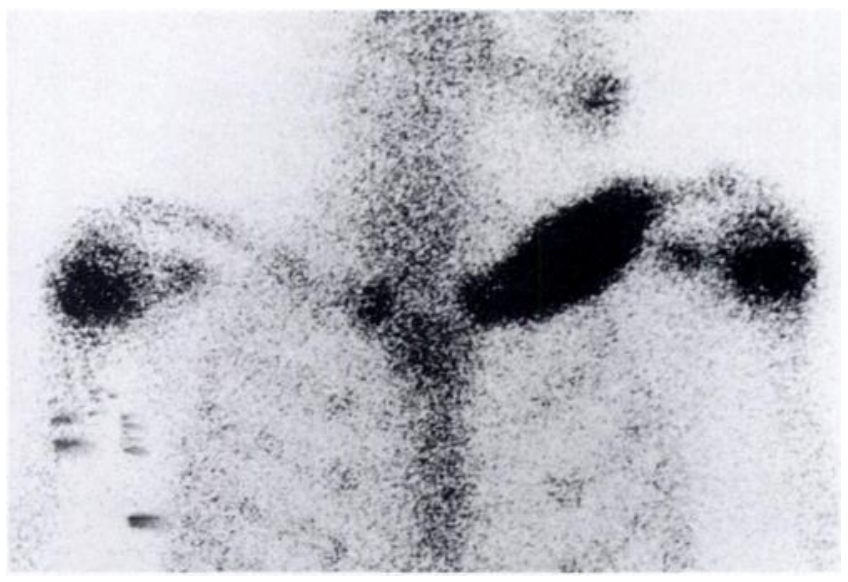

Fig. 10

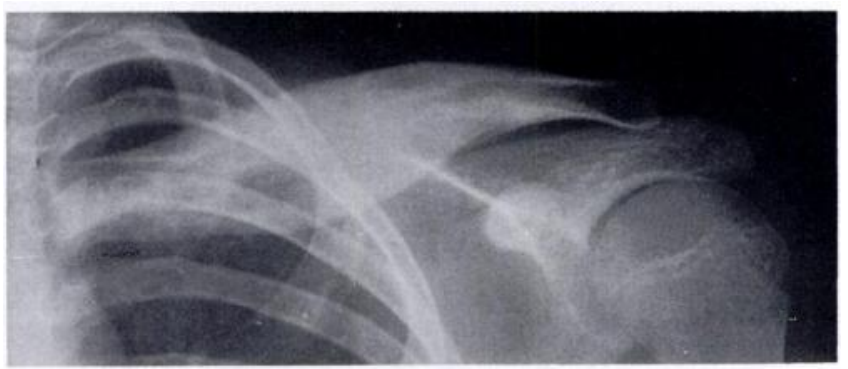

Fig. 12

Cone RO, Resnick D, Goergen TG, et al. Condensing osteitis of the clavicle. $A J R$ 1983:141:387-8.

Donovan RM, Shah KJ. Unusual sites of acute osteomyelitis in childhood. Clin Radiol 1982; 33:222-30.

Duró JC, Estrada P, Ribas D, Bartrons S, Rotés-Querol J. Condensing osteitis of the clavicle [letter]. Arthritis Rheum 1981:24:1454-5.

Franklin JL, Parker JC, King HA. Nontraumatic clavicle lesions in children. J Pediatr Orthop 1987; 7:575-8.

Franquet T, Lecumberri F, Rivas A, Inaraja L, Idoate MA. Condensing osteitis of the clavicle: report of two new cases. Skeletal Radiol 1985: 14:184-7.

Healey JH, Lane JM, Erlandson RA, Bullough PG. Solid leukemic tumor: an uncommon presentation of a common disease. Clin Orthop 1985; 194:248-51.

Kruger GD, Rock MG, Munro TG. Condensing osteitis of the clavicle: a review of the literature and report of three cases. $J$ Bone Joint Surg [Am] 1987; 69-A :550-7.

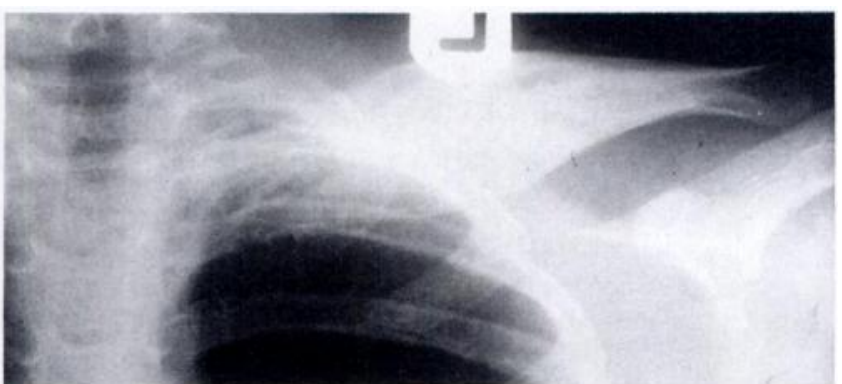

Fig. 9

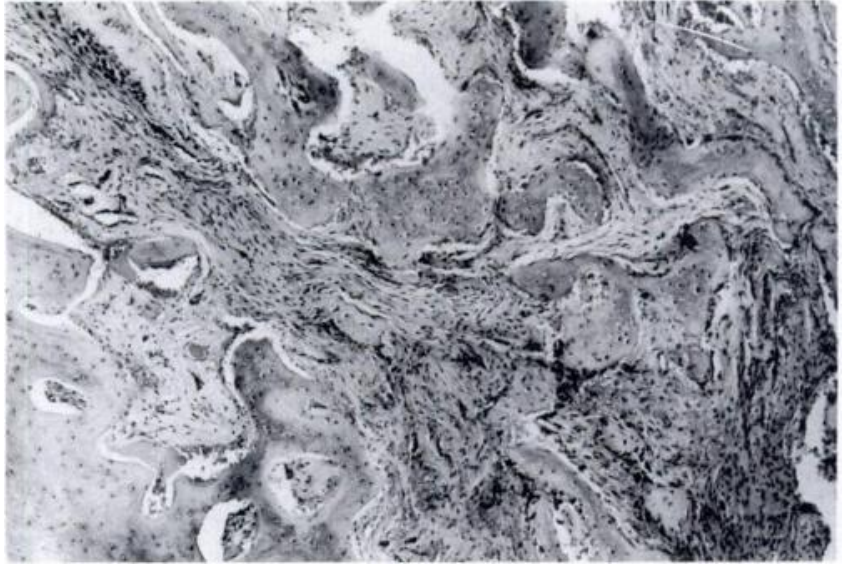

Fig. 11

Case 3. Figure 8 - At onset the radiograph showed periosteal reaction and early expansion of the mid clavicle. Figure 9 - Seven months later there was a large expansion of dense amorphous bone. Figure 10 - An isotope scan showed increased uptake in the abnormal area. Figure 11 - Histology showed mature (left) and immature bone (right) with osteoclastic activity and mild lymphocytic infiltrate $(H \& E \times 40)$. Figure 12 - Seven months later, the bony swelling was becoming smaller.
Mollan RAB, Craig BF, Biggart JD. Chronic sclerosing osteomyelitis: an unusual case. J Bone Joint Surg [Br] 1984; 66-B :583-5.

Petersen JK. Ostitis condensans claviculae. Ugeskr Laeger 1980; 142:1875-6. (Eng. abstr.)

Solovjev M. Ostitis condensans claviculae. Fortschr Geb Rontgenstr Nuklearmed Erganzungshand 1976; 125:375-6.

Simpson AJ. Positive bone scintigraphy in condensing osteitis of the clavicle. Clin Nucl Med 1978: 3:204.

Smith J, Yuppa F, Watson RC. Primary tumors and tumor-like lesions of the clavicle. Skeletal Radiol 1988; 17:235-46.

Teates CD, Brower AC, Williamson BRJ, Keats TE. Bone scans in condensing osteitis of the clavicle. South Med J 1978: 71 :736-8.

Tilly G, Audran M, Le Bodic MF, et al. Ostéite condensante de l'extrémité interne de la clavicule. A propos d'un nouveau cas. $J$ Radiol 1978: 59:223-6. (Eng. abstr.)

Weiner SN, Levy M, Bernstein R, Morehouse H. Condensing osteitis of the clavicle. J Bone Joint Surg [Am] 1984; 66-A :1484-6. 